\title{
Structure of bacterial communities in aquatic systems as revealed by filter PCR
}

\author{
David L. Kirchman ${ }^{1, *}$, Liying Yu ${ }^{1}$, Bernhard M. Fuchs ${ }^{2}$, Rudolf Amann ${ }^{2}$ \\ ${ }^{1}$ College of Marine Studies, University of Delaware, 700 Pilottown Road, Lewes, Delaware 19958, USA \\ ${ }^{2}$ Max-Planck-Institut für Marine Mikrobiologie, Celsiusstraße 1, 28359 Bremen, Germany
}

\begin{abstract}
Collection of microbial biomass and extraction of DNA are the first steps of many molecular approaches for examining uncultured microbes in aquatic ecosystems. Because of the difficulties of using large samples (up to $20 \mathrm{l}$ ) and the occasional ineffectiveness of DNA isolation procedures, we examined an alternative approach, 'filter PCR', which consists of filtering small volumes through polycarbonate filters and using sections of a filter directly in PCR. Positive amplification was achieved with as little as $25 \mu \mathrm{l}$ of coastal seawater, corresponding to about 10000 bacterial cells, although larger volumes (1 to $10 \mathrm{ml}$, depending on bacterial abundance) gave more consistent results. Denaturing gradient gel electrophoresis (DGGE) revealed few differences in the 16S rRNA amplicons from filter PCR and from the standard approach using DNA isolated from several liters of coastal seawater. A clone library of $16 \mathrm{~S}$ rRNA amplicons from filter PCR was slightly more diverse than a clone library constructed by the standard approach. These results allow us to explore variation in microbial community structure over a range of spatial scales and to examine the relative evenness of microbial communities in aquatic habitats. Our results indicate that filter PCR is as effective as the standard approach in retrieving bacterial genes from uncultured microbes in aquatic environments.
\end{abstract}

KEY WORDS: Bacterial community structure $\cdot$ Filter PCR · DGGE · Clone libraries · 16S rRNA

\section{INTRODUCTION}

Molecular approaches have revealed much about the diversity and function of uncultured microbes in natural aquatic ecosystems. Several of these approaches rely on PCR amplification of 16S rRNA or catabolic genes from DNA isolated from water samples without cultivation of the microbes. The first steps of these approaches, which include the collection of sufficient microbial biomass and then isolation and purification of DNA (Fuhrman et al. 1988, Giovannoni et al. 1990a), are often the most difficult ones. Occasionally, DNA isolated from environmental samples cannot be used in subsequent molecular analyses because of contamination by humics and other organic compounds isolated along with DNA. Even if useful DNA is isolated, the isolation method is time-consuming.

*E-mail: kirchman@udel.edu
Another nontrivial problem with the standard approach is that the sample volume is usually large, ranging from $500 \mathrm{ml}$ for eutrophic lakes (Bahr et al. 1996) and estuaries to 201 for open ocean samples (Fuhrman et al. 1988, Giovannoni et al. 1990a). This large volume can restrict the number of samples that can be taken from incubation experiments and even of in situ communities. Furthermore, the filtration time is usually substantial (h); oligotrophic water can be filtered quickly but more water needs to be filtered whereas the sample volume required for eutrophic systems is smaller but often filtration is slower because of high concentrations of detritus and organisms other than the targeted microbes. Although the bacterial community probably does not change during filtration, the long filtration time limits the number of samples that can be taken and complicates the collection of ancillary data. Thus, the sample volume and filtration time for the standard approach can restrict the application of molecular tools in extensive surveys of aquatic 
habitats and in experiments calling for multiple treatments or repeated sampling.

Recent environmental studies have used small samples and minimal DNA isolation (Anton et al. 2000, Bernard et al. 2000, Fuchs et al. 2000, Zubkov et al. 2001). Positive PCR amplification from small samples is not surprising, because it is well-known that PCR is sufficiently sensitive to detect even a single copy of a gene (Saiki et al. 1988). In addition, microbiologists have long used in PCR small subsamples of bacterial colonies without any prior cell lysis or purification of the DNA (Joshi et al. 1991). Although PCR is known to be possible with small samples and minimal DNA purification, the diversity of uncultured microbes revealed by this minimalist approach has not been compared to that retrieved by the more standard approach with purified DNA isolated from large samples.

The goal of this study was to determine whether PCR could be used with microbes collected on filters without any purification or prior treatment of the cells ('filter PCR'). The filter PCR method consists of filtering a small volume $(\leq 10 \mathrm{ml})$ of a water sample through a polycarbonate filter and using a section of that filter directly in PCR. The bacterial diversity revealed by the filter PCR approach with small samples ( $\leq 10 \mathrm{ml})$ was compared to that from the standard PCR approach with DNA isolated from 1 to 21 of coastal seawater. Our results indicate that the similarities in bacterial diversity recovered by the 2 approaches are more striking than any differences. The filter PCR approach could dramatically expand the application of PCR-based methods in microbial ecology.

\section{METHODS AND MATERIALS}

Bacterial strains. Pure cultures of bacteria representing some of the major groups found in aquatic ecosystems were used to test the filter PCR method (Table 1). Isolates with only a strain number were characterized by sequencing the 16S rRNA gene or by fluorescence in situ hybridization (Glöckner et al. 1999) in the case of the Cytophaga-Flavobacter strains. An additional 5 Gram-positive strains were isolated by suspending ca $1 \mathrm{~g}$ of soil (Lewes, DE) in $10 \mathrm{ml}$ of a low salt solution (de Boer et al. 1998) and plating a subsample onto trypticase soy agar. Random colonies were tested with the standard Gram stain. The Gram-positive bacteria were grown in trypticase soy broth, diluted to ca $3 \times$ $10^{6}$ cells $\mathrm{ml}^{-1}$, and tested in filter PCR.
PCR with filter sections. Typically seawater samples were preserved in formaldehyde $(2 \%$, final concentration) usually for $30 \mathrm{~min}$, and then various volumes of preserved samples (see 'Results') were filtered through $25 \mathrm{~mm}$ polycarbonate filters (Nuclepore or Poretics) with a $0.2 \mu \mathrm{m}$ pore size. Although it is often convenient to fix samples before processing, the fixation step is not necessary. The filters were rinsed 3 times with $2 \mathrm{ml}$ dionized water and then were frozen $\left(-20^{\circ} \mathrm{C}\right)$ until analysis. For filter PCR, the filters were cut into 8 equal sections. Parts of the filter with no sample were trimmed from the sections. One section was used per $\mathrm{PCR}$ reaction tube.

The conditions of filter PCR were the same as in standard PCR except that bovine serum albumin (BSA) was added; $3 \mu \mathrm{l}$ of BSA (stock concentration of $10 \mathrm{mg} \mathrm{ml}^{-1}$ ) was added per $100 \mu$ reaction. The form of BSA is important since positive amplification was obtained with 1 BSA preparation in filter PCR (Sigma A-7030) but not with another (Sigma B-8894). The added volumes (and stock concentrations) of dNTP (10 mM), $\mathrm{MgCl}_{2}(25 \mathrm{mM})$ and primers $(10 \mu \mathrm{M})$ were $2.5,10$, and $4 \mu \mathrm{l}$, respectively, for $100 \mu \mathrm{l}$ reactions. The Taq polymerase (2.5 units per reaction) was from Promega which also provided the $10 \times$ buffer. Thermal cycling conditions typically consisted of a 'touchdown' series in which the annealing temperature decreased from 65 to $55^{\circ} \mathrm{C}$ (or other appropriate annealing temperatures) by $1^{\circ} \mathrm{C}$ degree per cycle, followed by 15 cycles at $55^{\circ} \mathrm{C}$, each for $1 \mathrm{~min}$. The denaturing step was $1 \mathrm{~min}$ at $95^{\circ} \mathrm{C}$ and the extension was $2.5 \mathrm{~min}$ at $72^{\circ} \mathrm{C}$.

DNA isolation and DGGE analysis. To determine whether the filter PCR approach reveals the same diversity as the standard approach, denaturing gradient gel electrophoresis (DGGE) was used on samples taken from the mid-Atlantic coast (incoming high tide, Indian River Inlet, DE) on 2 dates, November 7, 1999 and May 8, 2000. Samples were first pre-filtered through $3.0 \mu \mathrm{m}$ (pore size) filters to remove organisms

Table 1. Bacterial isolates tested for filter PCR. All strains yielded positive amplification when tested individually in filter PCR. Another 6 Gram-positive isolates, which are not given in this table, were also positive

\begin{tabular}{|lccc|}
\hline Strain & Classification & Source & Reference \\
\hline MAMA 021 & $\alpha$-proteobacteria & M. A. Moran & González \& Moran (1997) \\
MAMA E37 & $\alpha$-proteobacteria & M. A Moran & González \& Moran (1997) \\
dB94 & $\beta$-proteobacteria & W. de Boer & de Boer et al. (1998) \\
F5 & $\beta$-proteobacteria & Å. Hagström & Hagström et al. (2000) \\
Vibrio harveyi & $\gamma$-proteobacteria & R. Belas & Belas et al. (1982) \\
Alteromonas 07 & $\gamma$-proteobacteria & H. Tsujibo & Tsujibo et al. (1993) \\
IRI 113 & Cytophaga-Flavobacter & M. Cottrell & Unpubl. \\
IRI 126 & Cytophaga-Flavobacter & M. Cottrell & Unpubl. \\
dB95 & Gram-positive & W. de Boer & de Boer et al. (1998) \\
dB177 & Gram-positive & W. de Boer & de Boer et al. (1998) \\
\hline
\end{tabular}


larger than bacteria, mainly phytoplankton, in order to minimize amplification of 16S rRNA genes in plastids of eukaryotes. About $85 \%$ of the bacterioplankton was in the $<3.0 \mu \mathrm{m}$ size fraction as determined by DAPI direct count epifluorescence microscopy (Porter \& Feig 1980). Samples for filter PCR were prepared as described above.

To isolate bacterioplankton DNA for PCR and DGGE analysis, the $<3.0 \mu \mathrm{m}$ size fraction (ca $10 \mathrm{l}$ ) was filtered onto Millipore Durapore filters $(0.22 \mu \mathrm{m}$, type GVWP) which were stored frozen at $-80^{\circ} \mathrm{C}$ in a storage buffer (Giovannoni et al. 1990b). Frozen filters were thawed and cells were lyzed using sodium dodecyl sulfate and Proteinase K for $3 \mathrm{~h}$. The lysate was extracted sequentially with phenol-chloroform and chloroform. The DNA was precipitated in sodium acetate and ethanol, and the precipatant was collected by centrifugation.

Amplicons from filter PCR and PCR with isolated DNA were analyzed by standard DGGE methods (Muyzer et al. 1993) using 6\% acrylamide gels containing a 30 to $70 \%$ gradient of formamide and urea. Two sets of primers were used (Muyzer et al. 1995): 358GC (GCG CCG CCG CGC CCC GCG CCC GTC CCG CCG CCC CCG CCC G CCT ACG GGA GGC AGC AG) and 907 RM (CCGTCAATT CMT TTG AGT TT) and 358GC and 517R (ATT ACC GCG GCT GG). Electrophoresis was performed at $60^{\circ} \mathrm{C}$ for $20 \mathrm{~h}$ at 100 V using a BioRad Dcode DGGE apparatus. The gel format was $14.5 \mathrm{~cm}$ wide, $20 \mathrm{~cm}$ long and $0.75 \mathrm{~mm}$ thick. Standards consisted of partial 16S rRNA genes from a Cytophaga-Flavobacter isolate IRI 113 (top band), Alteromonas 07 (middle band), and a Grampositive isolate dB95 (bottom band). These genes were amplicons from a PCR with the same DGGE primers as used for the samples. After staining with ethidium bromide, images of the DGGE gels were taken with the Kodak Electrophoresis Documentation and Analysis System 120 and then the negative (i.e. black bands on a white background) was recorded to optimize clarity. Irrelevant lanes and the top and bottom sections of the gels were cropped in Corel Photohouse.

DGGE analysis of pure culture mixtures. Ten bacterial strains (see 'Results') were grown in overnight cultures and used either singularly or in a mixture in filter PCR with the 358GC and 517R primers. The bacterial cultures were diluted to about $3 \times 10^{6}$ cell ml ${ }^{-1}$ before filtration. The cultures were also mixed (each at $3 \times 10^{6}$ cell $\mathrm{ml}^{-1}$ ), filtered, and the filter sections subjected to filter PCR. Genomic DNA was isolated from these strains and used as templates (50 ng strain ${ }^{-1}$ ) in regular PCR with the 358GC and 517R primers. Genomic DNA from these strains was also mixed (each at $50 \mathrm{ng}$ ) and then used in PCR. The amplicons from the various samples of filter PCR and PCR with isolated DNA were analyzed by DGGE as described above.
Construction of 16S rRNA gene libraries. To compare the diversity revealed by filter PCR and by the standard approach with isolated DNA, 2 gene libraries were constructed with PCR amplicons from the 2 approaches. The sample for these libraries was taken on an incoming tide from the Indian River Inlet, Delaware on May 8, 2000 (salinity about 30 psu). Samples for filter PCR were preserved, and DNA was isolated from about 2.01 and was extracted as described above. The PCR with filter sections and with isolated DNA was conducted with the universal bacterial primers EubB (AGA GTT TGA TCM TGG CTC AG) and EubA (AAG GAG GTG ATC CAN CCR CA) (Lane 1991). Two filter sections from a $10 \mathrm{ml}$ sample were used in filter PCR, and the PCR products were combined. The PCR products from both filter PCR and isolated DNA PCR were concentrated by centrifugation with Microcons (Amicon) and cloned with TOPOTA cloning kit with pCR2.1-TOPO (Invitrogen), following the manufacturer's instructions.

One hundred white (insert-bearing) colonies were randomly picked from each library and re-tested by PCR with the M13 forward and reverse primers (priming sites flanking the cloned insert in the pCR2.1 vector) to eliminate false positives. Of the original 100 clones, 92 and 98 remained positive in the filter PCR library and isolated DNA library, respectively. To screen the 2 libraries, amplicons from the M13 primedPCR of plasmids from each clone were digested with a mixture of the restriction enzymes HhaI and RsaI (New England Biolab). The restriction fragments were separated by agarose gel electrophoresis using $2 \%$ Metaphore agarose (FMC). Clones with identical restriction patterns were grouped together into clone families. Clones from a couple of families represented by several clones were re-tested by restriction enzyme digestion to confirm that they belonged to the correct family.

The distribution of clones in gene families in the 2 libraries was compared with a $\mathrm{R} \times \mathrm{C}$ likelihood ratio test, using a Monte Carlo method to obtain an unbiased estimate of the exact p-value, based on a Monte Carlo sample of 10000 tables from the reference set. The software used for this statistical test was StatXact 4 for Windows (CYTEL, Cambridge, MA).

Nucleotide sequencing. Subsamples of selected bands from DGGE gels were re-amplified with appropriate primers and re-analyzed by DGGE to confirm that the PCR product was from the correct band. The product from the second PCR was then used in the sequencing reaction. Nucleotide sequencing was performed using an ABI PRISM 310 (Perkin-Elmer) genetic analyzer and ABI PRISM Big Dye terminator cycle sequencing reagent. Representatives from some of the clone families were partially sequenced using 
the EubB and 517R primers (Lane 1991). Nucleotide sequences were analyzed by using BLAST (Version 2.1; National Center for Biotechnology Information [available at: www.ncbi.nlm.nih.gov/BLAST/]).

\section{RESULTS}

The first step in the standard approach for examining 16S rRNA genes in aquatic ecosystems is to extract DNA from particulate material collected on filters or filter cartridges from several liters of water. Since the sample volume can be prohibitively large and the extraction step time-consuming and sometimes ineffective, we explored an alternative approach that takes full advantage of the sensitivity of the PCR step. In brief, small volumes of seawater $(\leq 10 \mathrm{ml})$ were filtered through polycarbonate filters, and a section of the filter was used directly in PCR. Fig. 1 illustrates some typical results from the filter PCR approach using GC358F and 907RM as primers. A positive reaction was detected in a EtBr-stained agarose gel when the sample was as small as $25 \mu \mathrm{l}$ of coastal seawater, although replication was better with $100 \mu \mathrm{l}$ of this particular sample (Fig. 1) and larger volumes for other samples (see below). The relative amount of the amplicon appears to increase with the filter volume (Fig. 1). Since the number of bacteria in the original sample was $3.6 \times 10^{6} \mathrm{ml}^{-1}$ and the filter section was about an eighth of the total, a PCR amplicon was detected with about 10000 bacteria in the $25 \mu$ sample.
A

B

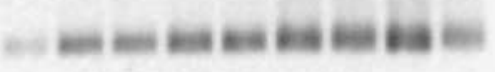

Fig. 1. Example of filter PCR (EtBr-stained agarose gel) using primers GC358F and 907RM to amplify a portion of the 16S rRNA gene. One filter section (about one-eighth of a filter) was used per reaction in duplicate. Three negative controls (-) included a reagent-only sample, a dry filter section, and a section of a filter through which particle-free seawater had been passed. The positive control (+) was from a PCR with DNA isolated from Alteromonas 07 . The volume of the PCR reaction loaded in all sample lanes was the same. (A) Filters were frozen before $\mathrm{PCR}_{i}(\mathrm{~B})$ filters were not frozen before PCR

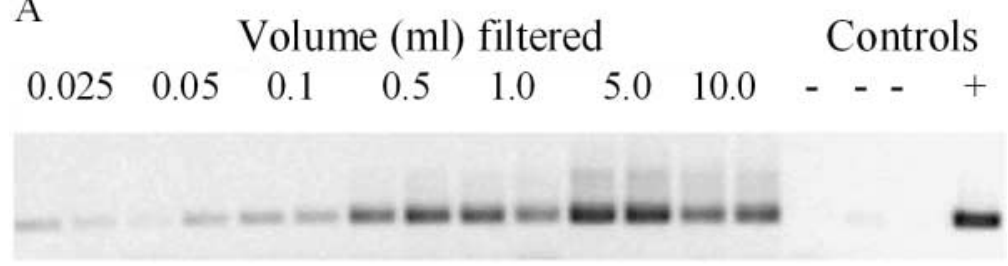

No product was detected in a negative control consisting of a dry filter section nor in a reagent-only sample (Fig. 1). In addition, no product could be detected in another negative control consisting of a filter which had filtered water $(0.22 \mu \mathrm{m}$ pore size; Acrodisk, Gelman) passed through it.

Positive amplification in filter PCR was achieved with freshwater samples (Hudson River), but not with a sediment slurry (ca $1 \mathrm{~g}$ sediment resuspended in $0 \mathrm{ml}$ ). Amplification in filter PCR was sometimes eaker than expected for the observed bacterial abunnce in samples from the Roosevelt Inlet (data not wn), a highly turbid harbor with large amounts of isom these waters is sometimes resistant to further molecular manipulations (Moore 1999). These pounds that inhibit DNA polymerases.

Microscopic analysis revealed that about $70 \%$ of coastal marine bacteria were removed from a filter section after going through a typical PCR run. We also tested the effect of PCR on 2 pure bacterial cultures which we could add in large enough densities for subsequent microscopic analysis. All cells of a Gram-negative strain (Vibrio harveyi) were completely lyzed in the PCR whereas a Gram-positive strain (dB95) seemed unaffected, even though filter PCR gives a positive amplification with this strain. Filter PCR yielded an amplicon with every pure culture strain tested (ca 20), including 8 Gram-positive strains.

\section{Sample storage and PCR conditions}

We typically fix samples in $2 \%$ formaldehyde since the samples are also used for fluorescence in situ hybridization (FISH) with oligonucleotide probes. After filtration, the polycarbonate filter is stored at $-20^{\circ} \mathrm{C}$. The freeze-thaw step does not seem to be necessary since filter samples analyzed immediately by PCR without any freezing also resulted in positive amplification (Fig. 1B). Similarly, PCR amplification was not affected by variations of the preservation procedure, such as different concentrations of formaldehyde $(0,2,3$ or $4 \%)$ or the purity of the formaldehyde; PCR amplification was similar with samples preserved in fresh formaldehyde prepared from paraformaldehyde typically used for preserving samples for FISH (Glöckner et al. 1999), buffered ultrapure formaldehyde, and unbuffered ultrapure formaldehyde 


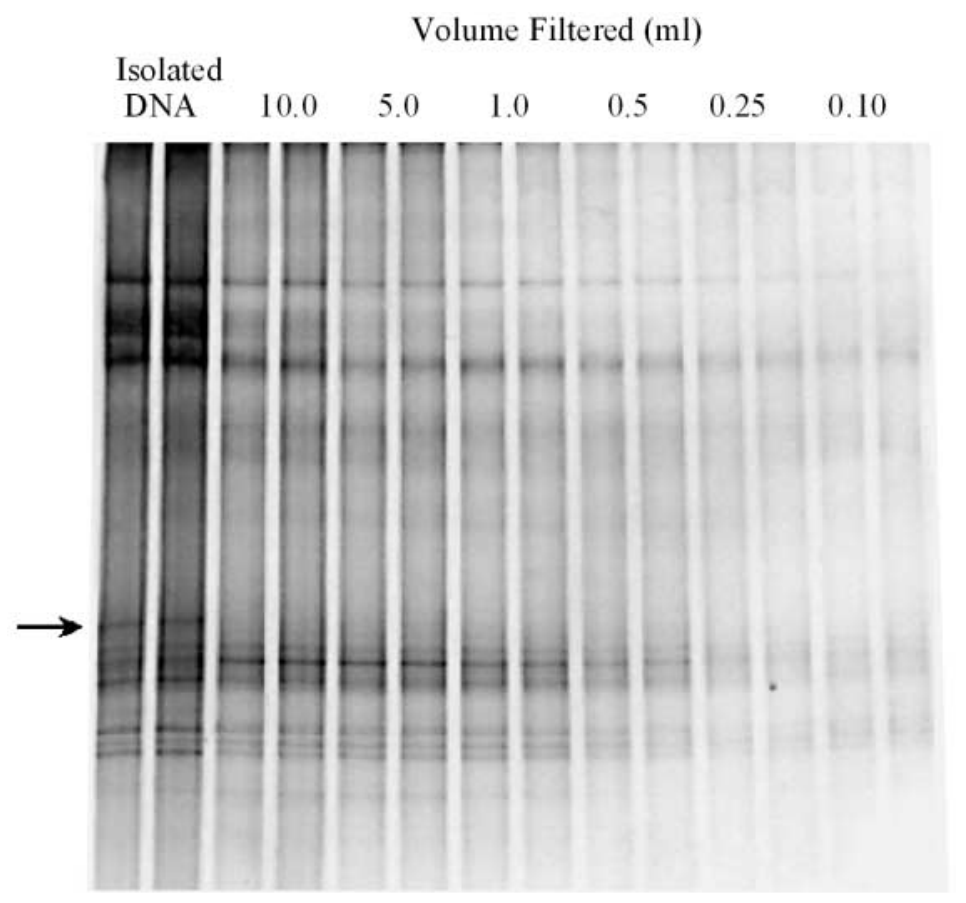

Fig. 2. DGGE gel of amplicons from PCR with isolated DNA and from filter PCR. The primers were GC358F and 907RM, which are specific for a portion of the 16S rRNA gene. The volume of the PCR reaction loaded in all sample lanes was the same. Arrow indicates a band found in the isolated DNA lane that is not obvious in the filter PCR lanes. Samples taken in November 1999

(Polyscience, Inc.). In these tests, the filter was frozen after the fixation step and then thawed before PCR. Fixing the sample is often convenient, but it is not necessary for successful filter PCR. It is desirable to avoid formaldehyde because it can inhibit amplification and lead to artifacts (Degiorgi et al. 1994).

During the development of this approach, we examined a number of variables that potentially could affect the efficacy of the PCR using a filter sample. The only parameter that seems crucial is the inclusion of BSA in the PCR step; filter PCR failed without BSA. One preparation of BSA (Sigma A-7030) worked in our hands, but another (Sigma B-8894) did not give a positive amplification. Several other studies have shown the effectiveness of BSA with difficult samples (e.g. Hagelberg et al. 1989). We have obtained positive PCR amplification using a variety of PCR primers, including 2 different sets commonly used in DGGE analyses (see below), EubA and EubB which are used for amplifying nearly the entire 16S rRNA gene (see below), and a16S rRNA primer (1406) paired with a 23S rRNA primer (Borneman \& Triplett 1997, Acinas et al. 1999). The amounts of amplicon from these reactions varied, but this was due to the PCR itself, not the filter. The presence of the filter does not affect the PCR when the tem- plate is isolated DNA or unextracted samples from a pure bacterial colony (results not shown).

\section{Diversity of PCR amplicons from filter PCR: DGGE analysis}

We hypothesized that only a fraction of natural bacterial communities is sampled by filter PCR, i.e. those cells whose DNA is accessible to the PCR reagents. If so, then the diversity of PCR amplicons from filter PCR would be much less than the diversity from isolated DNA. To test this hypothesis, we used DGGE to compare amplicons from filter PCR and from a PCR with bacterioplankton DNA isolated from the same water sample.

Both filter PCR and isolated DNA PCR resulted in nearly the same number and relative amounts of amplicons from samples on 2 dates. In November, 10 bands were distinct and dominant in the DGGE gel of the amplicons from a PCR with GC358F and 907RM (Fig. 2). Of these 10 bands, only 1 from the isolated DNA lane is not visible among the bands in the filter PCR lanes (Fig. 2). For the May sample, GC358F and 517R were used as primers because more subtle differences in samples may be apparent when the amplicon is smaller. In this sample, there are no apparent differences in the 2 sets of DGGE bands (Fig. 3). These results indicate that both filter PCR and isolated DNA PCR reveal the same bacterial diversity in aquatic systems and that there is no obvious bias due to using filter sections in PCR without DNA extraction.

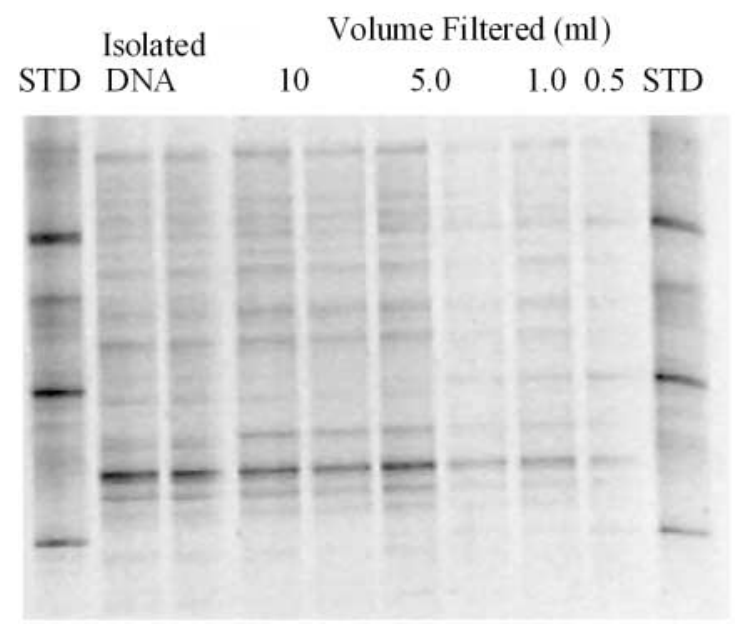

Fig. 3. DGGE gel of amplicons from PCR with isolated DNA and from filter PCR. The primers were GC358F and 517R for a portion of the 16S rRNA gene. Standards (STD) were amplicons from 3 bacterial isolates. The volume of the PCR reaction loaded in all sample lanes was the same. Samples taken in May 2000 
Some of the more prominent bands in the DGGE gels were excised and sequenced in order to determine if the communities we sampled were unusual in any respect. In the November sample, the sequence from 1 band found in both the isolated DNA and filter PCR lanes had the highest similarity (99\%) to an uncultured high G + C Gram-positive organism (Actinomycete OCS155; AF001652). The other bands represent various members of the alpha subdivision of proteobacteria which often dominate bacterial communities revealed by PCR-based approaches (Giovannoni \& Rappé 2000). These results and other data from the clone libraries (see below) confirm that the uncultured organisms sampled by both the filter PCR and the standard method with isolated DNA were not unusual compared with previous studies.

\section{Filter PCR of pure bacterial cultures}

To examine in greater detail whether filter PCR would successfully amplify $16 \mathrm{~S}$ rRNA from all bacterial types, several bacterial strains were grown to late exponential phase, diluted to the abundance typically

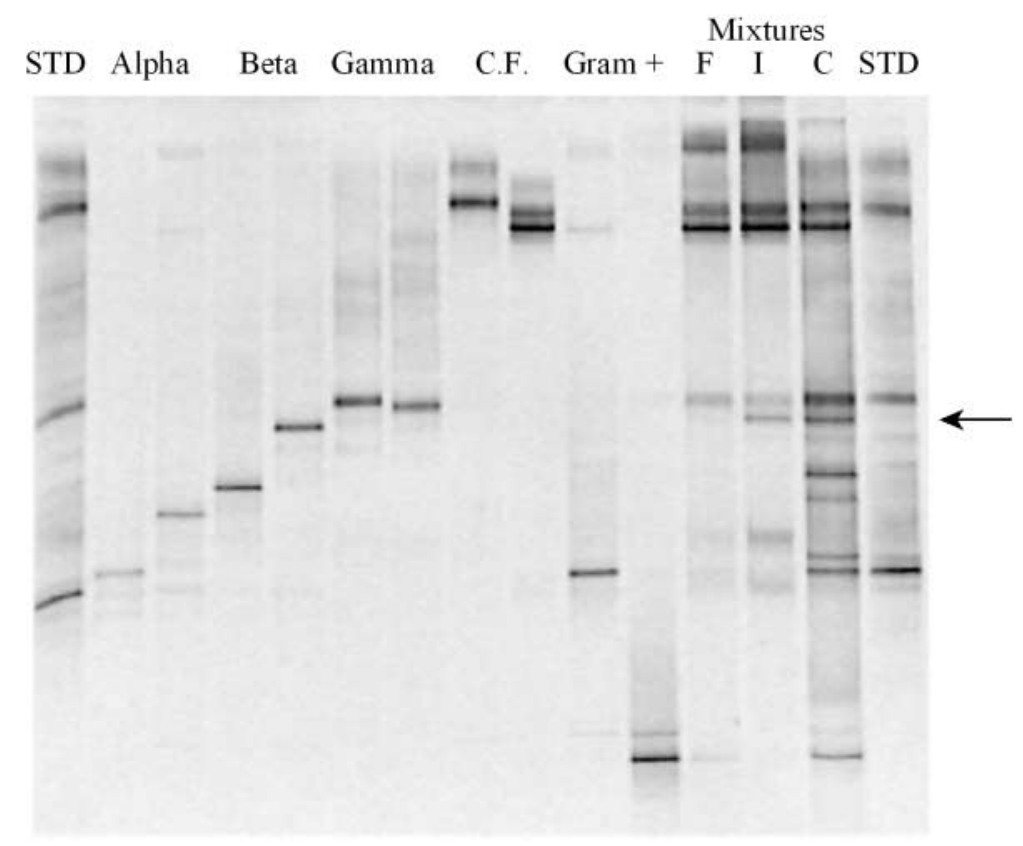

Fig. 4. DGGE gel of 16S rRNA genes from pure bacterial isolates analyzed either separately or in mixtures. Isolates are given in Table 1. Mixtures consisted of: (1) the strains mixed together, filtered, and then subjected to filter PCR $(F) ;(2)$ isolated DNA from each strain was mixed and then used a template in normal PCR (I); and (3) amplicons from the bacterial isolates were mixed after PCR in order to test the resolving power of the DGGE gel (C). Arrow indicates a band observed in the isolated DNA mixture that is not obvious in the mixed strain filter PCR lane found in aquatic habitats, and filtered as for water samples from natural coastal seawater. A positive PCR product was obtained from the 20 bacterial strains that were tested (Fig. 4 shows 10 strains).

To mimic complex natural communities, 10 bacterial strains were mixed, filtered together, and the filter sections analyzed by PCR and DGGE. Similarly, isolated DNA from the 10 strains was also mixed and the PCR amplicons analyzed by DGGE. As with the natural samples, the DGGE gel lanes from filter PCR and with isolated DNA were similar; only 1 band (from 1 of the 2 $\beta$-proteobacteria tested) presented in the isolated DNA lane was absent from the filter PCR lane (Fig. 4). Both procedures, however, did not recover all of the added bacteria (Fig. 4), but this ineffectiveness was not due to the filter in PCR. Not all bacterial strains were evident in the DGGE analysis of genomic DNA mixed together. With the exception of 1 strain, these results indicate that filter PCR introduces few if any additional biases compared with the standard approach.

One sample illustrates the limits of the resolution of the DGGE analysis which affects our ability to evaluate the amplicons obtained by filter PCR (Fig. 4). Even when 16S rRNA amplicons were obtained from pure cultures and then mixed together after PCR, the DGGE analysis could resolve only 9 of the 10 strains added together. The $2 \gamma$-proteobacteria and 1 of the $\beta$-proteobacteria migrated very close together, as did the strains from the Cytophaga-Flavobacter cluster, making it difficult to resolve them by DGGE.

\section{Clone libraries from filter and isolated DNA PCR}

We constructed 2 clone libraries of 16S rRNA genes: one of PCR amplicons from filter PCR (10 ml sample) and the other of amplicons from a PCR with DNA isolated from about 21 of the same water sample. After the initial screening of 100 clones, 92 and 98 positive clones in the filter and isolated DNA libraries, respectively, were screened by restriction enzyme digests to determine the diversity of 16S rRNA genes in the 2 libraries. Most of the clones in both libraries were unique and contained a rRNA gene not similar, based on restriction enzyme digests, to any other 16S rRNA gene in the 2 libraries. However, both libraries had a few $16 \mathrm{~S}$ rRNA gene families represented by more than one clone (Fig. 5). The distribution of clones per family in the filter and isolated DNA libraries is statistically the same (chi-square test; $\mathrm{p}=0.518)$. 
Table 3. Summary of clone families in libraries of 16S rRNA genes retrieved by filter PCR and from PCR with isolated DNA

\begin{tabular}{|c|c|c|c|c|}
\hline & Filter PCR & $\%$ of total ${ }^{\mathrm{a}}$ & Isolated DNA & $\%$ of total \\
\hline Number of clones & 92 & - & 97 & - \\
\hline Total clone families & 67 & 100 & 62 & 100 \\
\hline Unique clone families ${ }^{\mathrm{b}}$ & 51 & 76 & 46 & 74 \\
\hline Common clone families ${ }^{c}$ & 16 & 24 & 16 & 26 \\
\hline \multicolumn{5}{|c|}{${ }^{a}$ Percent of total gene families for each library } \\
\hline \multicolumn{5}{|c|}{${ }^{\mathrm{b}}$ Gene families present in only 1 of the 2 libraries } \\
\hline \multicolumn{5}{|c|}{${ }^{\mathrm{C}}$ Gene families present in both libraries (filter PCR and isolated DNA) } \\
\hline
\end{tabular}

the detection limit of the PCR and DGGE analysis. We know that the detection limit for filter PCR is in the order of 10000 bacteria. Wallner et al. (1997) reported some variation in detection limits for PCR amplification of 16S rRNA genes from whole cells isolated by flow cytometry. Their detection limits were 500 and 1000 cells for E. coli and Bacillus subtilis, respectively. Even given a 2-fold variation in detection limits, one would still expect some ribotypes to become undetectable as sample volume decreased from 1000 to $0.1 \mathrm{ml}$, if the community were unevenly distributed. The lack of

of amplicons from the standard approach with DNA isolated from about 21 of coastal seawater. In addition, the clone library from the filter PCR approach was slightly more diverse than that from the standard approach. Both sets of data suggest that the filter PCR is a viable and potentially powerful approach for sampling uncultured microbes in aquatic habitats.

One application of the filter PCR approach is to examine hypotheses about variation in bacterial communities on small spatial scales (Müller-Niklas et al. 1996, Azam 1998, Seymour et al. 2000, Long \& Azam in press). In our study, the ribotypes and level of microbial diversity we were able to observe in these coastal assemblages were in samples with volumes that varied at least 4 orders of magnitude $(0.1$ to $>1000 \mathrm{ml})$. However, any differences over the spatial scales covered by these volumes may have been minimized by the $3 \mu \mathrm{m}$ prefiltration.

Our results can also be used to examine the relative abundance of various ribotypes sampled by PCR, i.e. the evenness of the microbial community. Evenness cannot be examined directly with the clone library and DGGE data because of biases associated with PCR and cloning (Wintzingerode et al. 1997). However, one would still expect rare ribotypes to disappear from the DGGE gels as sample size decreases and the rare ribotypes drop below any observable change in DGGE bands argues against these gels being dominated by a few dominant ribotypes and many rarer ones, i.e. a very uneven bacterial community.

In contrast to the DGGE analysis, the clone library results seem to indicate differences between filter PCR and the standard approach. Although the 2 libraries had roughly similar levels of diversity and distributions of clones per clone family, only about $25 \%$ of all clones were found in both libraries, suggesting that the filter PCR and standard approach did not sample the same bacterial community. Some differences may arise due to random sampling of a diverse community; the reproducibility of clone library construction is unknown. In addition, because of the small sample volume, the filter PCR library would not include rare bacteria that are potentially represented in the isolated DNA library. It seems unlikely, however, that the large differences between the 2 libraries could be due to chance or rare bacteria. The exclusion of rare bacteria, if important, should have lead to lower overall diversity in the filter PCR library, but in fact diversity was slightly higher than that of the isolated DNA library. The 4 diversity indices for our libraries were only somewhat smaller than those reported for a soil community (Table 2), often considered the most diverse in the biosphere.

Table 4. Analysis of selected clones from clone libraries constructed with amplicons from filter PCR or from a PCR with isolated DNA. The clones were either from the filter (e.g. F-22) or the isolated DNA library (e.g. I-1). The closest match was determined by a BLAST analysis of GenBank

\begin{tabular}{|lcccccc|}
\hline $\begin{array}{l}\text { Sequenced } \\
\text { clone }\end{array}$ & $\begin{array}{c}\text { No. of clones } \\
\text { Filter PCR Isolated DNA }\end{array}$ & Closest match & \multicolumn{2}{c|}{$\begin{array}{c}\text { Similarity } \\
\text { Accession } \\
\text { no. }\end{array}$} & Reference \\
\hline F-22 & 4 & 0 & Unidentified $\alpha$-proteobacterium OM42 & 0.98 & U70680 & Rappé et al. (1997) \\
F-28 & 4 & 0 & Uncultured $\gamma$-proteobacterium ZD0424 & 0.95 & AJ400355 & Zubkov et al. (2001) \\
I-1 & 6 & 7 & Uncultured $\alpha$-proteobacterium CRE-PA70 & 0.98 & AF141539 & Crump et al. (1999) \\
F-4 & 4 & 4 & Uncultured Roseobacter & 0.99 & AF245632 & González et al. (2000) \\
F-26 & 2 & 9 & Unidentified $\alpha$-proteobacterium GAI-36 & 0.99 & AF007259 González \& Moran (1997) \\
I-88 & 0 & 4 & Uncultured $\alpha$-proteobacterium CRE-PA70 & 0.99 & AF141539 & Crump et al. (1999) \\
I-5 & 0 & 9 & Uncultured marine $\alpha$-proteobacterium OM242 & 0.98 & U70689 & Field et al. (1997) \\
\hline
\end{tabular}


The differences between the 2 clone libraries seem to contradict the results from the DGGE analyses; DGGE gels from filter PCR and the standard approach were identical, or nearly so. We are not aware of a study that has directly compared clone library and DGGE results, but it seems reasonable to expect that abundant ribotypes would be equally represented by both approaches (ignoring biases for now) and that rare ribotypes would be more prominent in clone libraries than in DGGE gels. The rare ribotypes probably result in weak bands that are not obvious, if visible at all, on a DGGE gel with several dark bands. These numerous but individually rare ribotypes would result in many unique clones in a clone library of $16 \mathrm{~S}$ rRNA genes, and indeed most ribotypes (>75\%) in our libraries were represented by a single clone, found in only 1 library. Even so, we would expect that the libraries from 2 samples with similar DGGE profiles should have the large gene families in common, i.e. those families represented by several clones. This was not the case. Both libraries had large gene families that were found in one library but not the other. Furthermore, none of the sequences of the dominant DGGE bands were similar to sequenced $16 \mathrm{~S}$ rRNA genes in the 2 clone libraries.

The biases associated with PCR-based methods are well known, and a recent study indicates that the community structure implied by clone libraries can be substantially different from that revealed by fluorescence in situ hybridization (FISH) in coastal systems (Cottrell \& Kirchman 2000). The fidelity of DGGE and other fingerprint methods in representing the phylogenetic composition of bacterial communities is not known, but the differences we see between DGGE and clone library results suggest that different biases are associated with these 2 molecular methods. Divergence of the 2 methods may start at the PCR step since different primers are used. The ligation and cloning steps may introduce additional biases during construction of clone libraries. Of course, these biases are present in both filter PCR and the standard approach with isolated DNA. Given our present understanding of microbial diversity, results from DGGE (and probably other DNA fingerprint methods) and clone libraries produced by the filter PCR approach appear to be as valid as results from the standard approach in examining uncultured microbial assemblages in aquatic environments.

Another problem with the standard approach is unequal extraction of DNA from all microbes (Wintzingerode et al. 1997); other extraction procedures need to be tested. An analogous problem with filter PCR is whether or not the DNA from all bacteria would be equally accessible to the PCR reagents. In our study, amplification was positive for all pure cul- tures we tested by filter PCR. Similarly, Wallner et al. (1997) found that PCR of whole cells without DNA isolation was successful with 10 strains fixed by formaldehyde and 5 Gram-positive strains preserved with ethanol, but they did report negative results with 2 pure bacterial strains from the beta and gamma subdivision of proteobacteria. In our study, filter PCR did not recover all ribotypes from a mixture of 10 bacterial strains, but the standard approach with isolated DNA was almost equally inadequate. We think that this pure culture experiment (Fig. 4) illustrates problems with PCR and the DGGE analysis, not in trying to retrieve genetic material from filter sections.

Even given the biases and other problems, PCRbased methods will continue to be used in ecological studies. This study indicates that large samples are not essential for all PCR-based approaches. The filter PCR approach has several advantages over the standard method for obtaining DNA for molecular analysis. The time required for filtering $\leq 25 \mathrm{ml}$ is at least 10 -fold less than that for large volumes, and several (at least 12) samples can be filtered simultaneously on multiple-filter manifolds. If filtration is not possible immediately (e.g. because other samples or measurements have to be taken), water samples can be easily fixed and preserved for filtration at a more convenient time. Fixation of large volumes is certainly possible but is more cumbersome at best. Analogous to archiving isolated DNA for future analyses, several filters from a sample can be prepared, frozen and saved for filter PCR at a later date. Because of its ease and small sample size, the filter PCR method should greatly extend the application of PCR-based molecular methods in aquatic microbial ecology.

Acknowledgements. We thank Matthew Cottrell for his advice during this project and for his comments on the manuscript. We also thank M. A. Moran, W. de Boer, Å. Hagström, and $H$. Tsujibo for sending the strains listed in Table 1 and John Dunbar for sending us the rarefaction program. D.L.K. was a fellow at the Hanse Wissenschaftskolleg when this study was initiated. The work was supported by grants from the US Department of Energy (Biotechnological Investigations-Ocean Margins Program), the National Science Foundation, and the Max Planck Society.

\section{LITERATURE CITED}

Acinas SG, Anton J, Rodriguez-Valera F (1999) Diversity of free-living and attached bacteria in offshore western Mediterranean waters as depicted by analysis of genes encoding 16S rRNA. Appl Environ Microbiol 65:514-522

Anton J, Rossello-Mora R, Rodriguez-Valera F, Amann R (2000) Extremely halophilic Bacteria in crystallizer ponds from solar salterns. Appl Environ Microbiol 66:3052-3057

Azam F (1998) Microbial control of oceanic carbon flux: the plot thickens. Science 280:694-696

Bahr M, Hobbie JE, Sogin ML (1996) Bacterial diversity in an 
arctic lake: a freshwater SAR11 cluster. Aquat Microb Ecol 11:271-277

Belas R, Mileham A, Cohn D, Hilmen M, Simon M, Silverman M (1982) Bacterial bioluminescence: isolation and expression of the luciferase genes from Vibrio harveyi. Science 218:791-794

Bernard L, Schafer H, Joux F, Courties C, Muyzer G, Lebaron $P$ (2000) Genetic diversity of total, active and culturable marine bacteria in coastal seawater. Aquat Microb Ecol 23:1-11

Borneman J, Triplett EW (1997) Molecular microbial diversity in soils from eastern Amazonia: evidence for unusual microorganisms and microbial population shifts associated with deforestation. Appl Environ Microbiol 63: 2647-2653

Cottrell MT, Kirchman DL (2000) Community composition of marine bacterioplankton determined by 16S rDNA clone libraries and fluorescence in situ hybridization. Appl Environ Microbiol 66:5116-5122

Crump BC, Armbrust EV, Baross JA (1999) Phylogenetic analysis of particle-attached and free-living bacterial communities in the Columbia river, its estuary, and the adjacent coastal ocean. Appl Environ Microbiol 65:3192-3204

de Boer W, Gunnewiek P, Lafeber P, Janse JD, Spit BE, Woldendorp JW (1998) Anti-fungal properties of chitinolytic dune soil bacterial. Soil Biol Biochem 30:193-203

Degiorgi C, Sialer MF, Lamberti F (1994) Formalin-induced infidelity in PCR-amplified DNA fragments. Mol Cell Probes 8:459-462

Dunbar J, Takala S, Barns SM, Davis JA, Kuske CR (1999) Levels of bacterial community diversity in four arid soils compared by cultivation and 16S rRNA gene cloning. Appl Environ Microbiol 65:1662-1669

Field KG, Gordon D, Wright T, Rappé M, Urbach E, Vergin K, Giovannoni SJ (1997) Diversity and depth-specific distribution of SAR11 cluster rRNA genes from marine planktonic bacteria. Appl Environ Microbiol 63:63-70

Fuchs BM, Zubkov MV, Sahm K, Burkill PH, Amann R (2000) Changes in community composition during dilution cultures of marine bacterioplankton as assessed by flow cytometric and molecular biological techniques. Environ Microbiol 2:191-201

Fuhrman JA, Comeau DE, Hagström A, Chan AM (1988) Extraction from natural planktonic microorganisms of DNA suitable for molecular biological studies. Appl Environ Microbiol 54:1426-1429

Giovannoni SJ, Rappé MS (2000) Evolution, diversity and molecular ecology of marine prokaryotes. In: Kirchman DL (ed) Microbial ecology of the ocean. Wiley-Liss, Inc, New York, p 47-84

Giovannoni SJ, Britschgi TB, Moyer CL, Field KG (1990a) Genetic diversity in Sargasso Sea bacterioplankton. Nature 345:60-63

Giovannoni SJ, DeLong EF, Schmidt TM, Pace NR (1990b) Tangential flow filtration and preliminary phylogenetic analysis of marine picoplankton. Appl Environ Microbiol 56:2572-2575

Glöckner FO, Fuchs BM, Amann R (1999) Bacterioplankton compositions of lakes and oceans: a first comparison based on fluorescence in situ hybridization. Appl Environ Microbiol 65:3721-3726

González JM, Moran MA (1997) Numerical dominance of a group of marine bacteria in the alpha-subclass of the class Proteobacteria in coastal seawater. Appl Environ Microbiol 63:4237-4242

González JM, Simo R, Massana R, Covert JS, Casamayor EO,
Pedros-Alio C, Moran MA (2000) Bacterial community structure associated with a dimethylsulfoniopropionateproducing North Atlantic algal bloom. Appl Environ Microbiol 66:4237-4246

Hagelberg E, Sykes B, Hedges R (1989) Ancient bone DNA amplified. Nature 342:485

Hagström ^̊, Pinhassi J, Zweifel UL (2000) Biogeographical diversity among marine bacterioplankton. Aquat Microb Ecol 21:231-244

Joshi AK, Baichwal V, Ames GFL (1991) Rapid polymerase chain-reaction amplification using intact bacterial cells. Biotechniques 10:42-44

Lane DJ (1991) 16S/23S rRNA sequencing. In: Stackebrandt E, Goodfellow $M$ (eds) Nucleic acid techniques in bacterial systematics. John Wiley \& Sons, Ltd, New York, p 115-175

Long RA, Azam F (in press) Microscale patchiness in bacterial community richness in seawater. Aquat Microb Ecol

Moore JA (1999) Cloning and characterization of functional chitinases from marine bacterial communities. $\mathrm{MSc}_{\text {, }} \mathrm{Col}-$ lege of Marine Studies, University of Delaware, Newark, $\mathrm{DE}$

Müller-Niklas G, Agis M, Herndl GJ (1996) Microscale distribution of bacterioplankton in relation to phytoplankton: Results from 100-nl samples. Limnol Oceanogr 41: $1577-1582$

Muyzer G, De Wall EC, Uitterlinden AG (1993) Profiling of complex microbial populations by denaturing gradient gel electrophoresis analysis of polymerase chain reactionamplified genes coding for 16S rRNA. Appl Environ Microbiol 59:695-700

Muyzer G, Teske A, Wirsen CO, Jannasch HW (1995) Phylogenetic relationships of Thiomicrospira species and their identification in deep-sea hydrothermal vent samples by denaturing gradient gel electrophoresis of 16S rDNA fragments. Arch Microbiol 164:165-172

Porter KG, Feig YS (1980) The use of DAPI for identifying and counting aquatic microflora. Limnol Oceanogr 25:943-948

Rappé MS, Kemp PF, Giovannoni SJ (1997) Phylogenetic diversity of marine coastal picoplankton 16S rRNA genes cloned from the continental shelf off Cape Hatteras, North Carolina. Limnol Oceanogr 42:811-826

Saiki RK, Gelfand DH, Stoffel S, Scharf SJ, Higuchi R, Horn GT, Mullis KB, Erlich HA (1988) Primer-directed enzymatic amplification of DNA with a thermostable DNA polymerase. Science 239:487-491

Seymour JR, Mitchell JG, Pearson L, Waters RL (2000) Heterogeneity in bacterioplankton abundance from 4.5 millimetre resolution sampling. Aquat Microb Ecol 22: 143-153

Tsujibo H, Orikoshi H, Tanno H, Fujimoto K, Miyamoto K, Imada C, Okami Y, Inamori Y (1993) Cloning, sequence, and expression of a chitinase gene from a marine bacterium, Altermonas sp. strain O-7. J Bacteriol 175:176-181

Wallner G, Fuchs B, Spring S, Beisker W, Amann R (1997) Flow sorting of microorganisms for molecular analysis. Appl Environ Microbiol 63:4223-4231

Wintzingerode FV, Göbel UB, Stackebrandt E (1997) Determination of microbial diversity in environmental samples: pitfalls of PCR-based rRNA analysis. FEMS Microbiol Rev 21:213-229

Zubkov M, Fuchs BM, Archer SD, Kiene R, Amann R, Burkill PH (2001) Linking the composition of bacterioplankton to rapid turnover of dissolved dimethylsulphoniopropoinate in an algal bloom in the North Sea. Environ Microbiol 3: 304-311

Submitted: March 16, 2001; Accepted: July 16, 2001

Proofs received from author(s): September 21, 2001 